\title{
Hyperprogressive Disease in the Irradiation Field after a Single Dose of Nivolumab for Gastric Cancer: A Case Report
}

\author{
Takatsugu Ogata Hironaga Satake Misato Ogata Yukimasa Hatachi \\ Hisateru Yasui
}

Department of Medical Oncology, Kobe City Hospital Organization, Kobe City Medical Center General Hospital, Kobe, Japan

\section{Keywords}

Gastric cancer - Hyperprogressive disease - Pseudoprogression - Radiotherapy - Nivolumab · Immune checkpoint inhibitors

\begin{abstract}
Following the ATTRACTION-2 study, nivolumab was approved for advanced gastric cancer in Japan. However, pseudoprogression and hyperprogressive disease have been reported in patients treated with immune checkpoint inhibitors. We report a patient with gastric cancer who received nivolumab after radiotherapy only to experience rapid progression within the irradiation field after the first immunotherapy session. A 66-year-old man with dysphagia visited our hospital and was diagnosed with stage IV gastroesophageal cancer (human epidermal growth factor receptor-2 score $=0)$. He commenced a G-SOX regimen $\left(\mathrm{S}-180 \mathrm{mg} / \mathrm{m}^{2}\right.$ on days $1-14$ and oxaliplatin $100 \mathrm{mg} / \mathrm{m}^{2}$ on day 1 , repeated every 3 weeks) in June 2017. The dysphagia worsened despite 3 cycles of G-SOX, and computed tomography (CT) revealed constriction of the gastroesophageal junction. To ameliorate the dysphagia, palliative
\end{abstract}




\section{Case Reports in Oncology}

Case Rep Oncol 2018;11:143-150

DOI: $10.1159 / 000487477$

2018 The Author(s). Published by S. Karger AG, Base www.karger.com/cro

Ogata et al.: Hyperprogressive Disease in the Irradiation Field after a Single Dose of Nivolumab for Gastric Cancer: A Case Report

chemoradiotherapy (S-1 and 50.4 Gy in 28 fractions) was performed starting in August 2017. The patient's dysphagia had not resolved after completing radiotherapy, and pain on swallowing worsened. Nivolumab ( $3 \mathrm{mg} / \mathrm{m}^{2}$ every 2 weeks) was administered 7 days after the completion of radiotherapy. The patient experienced malaise and worsening dysphagia before the second cycle. CT 15 days after the first nivolumab administration revealed rapid progression in the irradiation field. His general condition rapidly deteriorated, and he died 24 days after the first administration. This episode suggests that administration of nivolumab after radiotherapy may be a risk factor for hyperprogressive disease.

(C) 2018 The Author(s)

Published by S. Karger AG, Basel

\section{Introduction}

Nowadays, immune checkpoint inhibitors are used to treat various types of tumors [13]. The ATTRACTION-2 study found that nivolumab administered to patients who were previously treated for advanced gastric cancer produces a significant survival benefit [4]. Nivolumab was approved for the treatment of advanced gastric cancer in Japan in September 2017. It has also been reported that immune checkpoint inhibitors administered after radiotherapy produce an abscopal effect [5]. Therefore, many clinical trials of combination therapies involving immune checkpoint inhibitors and radiotherapy are ongoing.

On the other hand, the activities of immune checkpoint inhibitors are different from those of cytotoxic agents; therefore, patients' responses to them are unique. Pseudoprogression and hyperprogressive disease have been reported in patients treated with immune checkpoint inhibitors [6-8]; specifically, hyperprogressive disease has to date been reported in lung and head and neck cancers $[7,8]$ but not in gastric cancer.

Here, we report a first-of-its-kind event in a patient with gastric cancer who was prescribed nivolumab after radiotherapy, whereupon he experienced rapid progression within the irradiation field following the first administration of this immune checkpoint inhibitor.

\section{Case Report}

A 66-year-old man with dysphagia visited our hospital. Upper gastrointestinal endoscopy revealed a tumor at the gastroesophageal junction; gastric mucosal biopsy revealed signet ring cell carcinoma and poorly differentiated adenocarcinoma. Immunohistochemistry for human epidermal growth factor receptor- 2 was negative (score $=0$ ). Computed tomography (CT) and positron emission tomography revealed metastasis to the regional and right hilar lymph nodes (Fig. 1). The patient was diagnosed with gastroesophageal cancer stage IV. He commenced a G-SOX regimen $\left(\mathrm{S}-1\left[80 \mathrm{mg} / \mathrm{m}^{2}\right.\right.$ on days $\left.1-14\right]$ plus oxaliplatin $\left[100 \mathrm{mg} / \mathrm{m}^{2}\right.$ on day 1]) in June 2017, with treatment repeated every 3 weeks [9]. Although 3 cycles of G-SOX were administered, his dysphagia worsened. CT revealed constriction of the gastroesophageal junction (Fig. 2). To improve the dysphagia, palliative chemoradiotherapy with S-1 and 50.4 Gy in 28 fractions was administered in August 2017; the irradiation field included the hilar lymph node, gastric cardia (primary lesion), and regional lymph nodes (Fig. 2). Radio- 


\section{Case Reports in Oncology}

(C) 2018 The Author(s). Published by S. Karger AG, Basel www.karger.com/cro

Ogata et al.: Hyperprogressive Disease in the Irradiation Field after a Single Dose of Nivolumab for Gastric Cancer: A Case Report

therapy was completed in October 2017 without interruption; however, the patient's dysphagia persevered and pain on swallowing worsened. This led to immediately prescribing systemic therapy with nivolumab $\left(3 \mathrm{mg} / \mathrm{m}^{2}\right.$ every 2 weeks) 7 days after the completion of radiotherapy, with which an abscopal effect was anticipated. Laboratory data on the first day of nivolumab administration are summarized in Table 1. CT findings before commencing nivolumab are shown in Figure 3a. However, the patient complained of malaise and worsening dysphagia before the second cycle. CT performed 15 days following the first administration of nivolumab revealed rapid progression in the irradiation field (Fig. 3b). The patient's general condition rapidly deteriorated, and he died 24 days after the first nivolumab administration.

\section{Discussion}

To the best of our knowledge, we are the first to report hyperprogressive disease in a patient with gastric cancer who was treated with nivolumab. Although the patient received nivolumab after radiotherapy, the disease nevertheless progressed rapidly, and he died within a month of the first administration of this agent. This case suggests that the administration of nivolumab after radiotherapy may be a risk factor for hyperprogressive disease.

The National Comprehensive Cancer Network guideline recommends 45-50.4 Gy or even higher doses for patients with positive surgical margins after gastrectomy [10]. However, radiotherapy is not considered a standard therapy for gastric cancer in Japan; nevertheless, locoregional control was required in our patient to alleviate his dysphagia, and all his lesions were treatable with a single radiation field. Therefore, a curative dose of 50.4 Gy of radiation was administered.

Combination therapy with paclitaxel and the antivascular endothelial growth factor receptor- 2 antibody ramucirumab is a recommended second-line treatment for advanced gastric cancer after progression following an S-1 based regimen. However, prior thoracic radiotherapy was reported to be a risk factor for hemoptysis in patients treated with bevacizumab [11]. Ramucirumab is similar to bevacizumab, and it was therefore not advisable to use it immediately after radiotherapy. Because his dysphagia persisted and pain on swallowing worsened, the patient required systemic therapy as soon as possible, hence the nivolumab treatment.

Immune checkpoint inhibitors function differently from cytotoxic agents, and pseudoprogression is one of the specific sequelae of these inhibitors. Pseudoprogression is defined as a transient increase in tumor size while undergoing immunotherapy for cancer [12] and is thought to be caused by edema or necrosis following T-cell infiltration into the tumor as well as continued tumor growth prior to the onset of the immune response [13]. Pseudoprogression was reported in patients with metastatic melanoma [6]; usually, the general conditions of patients who experience this phenomenon improve [12].

On the other hand, hyperprogressive disease has been previously reported in patients with lung and head and neck cancer [7, 8]. It is not clearly defined, but is sometimes described as an acceleration of the tumor growth rate following treatment with immune checkpoint inhibitors compared to previous treatments, as was the case with our patient. In a retrospective study, Saâda-Bouzid et al. [8] reported that hyperprogressive disease fre- 
quently occurred in patients with locoregional recurrence; almost all such patients in their study had undergone radiotherapy.

The mechanism of hyperprogressive disease is not clear. Radiotherapy causes the production of tumor antigens that alter the immune environment [14], which we hypothesize may facilitate rapid progression within the irradiation field. In gastric as well as head and neck cancers, recurrence within the irradiation field may be a risk factor for hyperprogressive disease.

The abscopal effect has been reported in patients treated with immune checkpoint inhibitors after radiotherapy. An abscopal effect in a patient with gastric cancer has been reported only by Sato et al. [15]; it occurred following radiotherapy plus concurrent adoptive T-cell immunotherapy. Abscopal effects may be very rare in patients with gastric cancer; when such patients require postradiotherapy treatment, alternatives to nivolumab may need to be considered.

In conclusion, our patient with gastric cancer is the first to experience rapid progression within the irradiation field following a single nivolumab treatment cycle after radiotherapy. This suggests that the administration of nivolumab after radiotherapy may be a risk factor for hyperprogressive disease.

\section{Statement of Ethics}

The Ethics Committee of Kobe City Medical Center General Hospital approved the study.

Written informed consent was obtained from the deceased's wife for publication of this case report and any accompanying images.

\section{Disclosure Statement}

The authors report no conflict of interest.

\section{Funding Sources}

Not applicable.

\section{References}

1 Novello S, Barlesi F, Califano R, Cufer T, Ekman S, Levra MG et al.; ESMO Guidelines Committee. Metastatic non-small-cell lung cancer: ESMO Clinical Practice Guidelines for diagnosis, treatment and follow-up. Ann Oncol. 2016 Sep;27 Suppl 5:v1-27.

2 Escudier B, Porta C, Schmidinger M, Rioux-Leclercq N, Bex A, Khoo V et al.; ESMO Guidelines Committee. Renal cell carcinoma: ESMO Clinical Practice Guidelines for diagnosis, treatment and follow-up. Ann Oncol. 2016 Sep;27 Suppl 5:v58-68.

3 Dummer R, Hauschild A, Lindenblatt N, Pentheroudakis G, Keilholz U; ESMO Guidelines Committee. Cutaneous melanoma: ESMO Clinical Practice Guidelines for diagnosis, treatment and follow-up. Ann Oncol. 2015 Sep;26 Suppl 5:v126-32. 
Ogata et al.: Hyperprogressive Disease in the Irradiation Field after a Single Dose of Nivolumab for Gastric Cancer: A Case Report

4 Kang YK, Boku N, Satoh T, Ryu MH, Chao Y, Kato K et al. Nivolumab in patients with advanced gastric or gastro-oesophageal junction cancer refractory to, or intolerant of, at least two previous chemotherapy regimens (ONO-4538-12, ATTRACTION-2): a randomised, double-blind, placebo-controlled, phase 3 trial. Lancet. 2017 Dec;390(10111):2461-71.

5 Brix N, Tiefenthaller A, Anders H, Belka C, Lauber K. Abscopal, immunological effects of radiotherapy: narrowing the gap between clinical and preclinical experiences. Immunol Rev. 2017 Nov;280(1):249-79.

6 Weber JS, O’Day S, Urba W, Powderly J, Nichol G, Yellin M et al. Phase I/II study of ipilimumab for patients with metastatic melanoma. J Clin Oncol. 2008 Dec;26(36):5950-6.

7 Ferrara R, Caramella C, Texier M, Audigier Valette C, Tessonnier L, Mezquita L et al. 1306PD hyperprogressive disease (HPD) is frequent in non-small cell lung cancer (NSCLC) patients (pts) treated with anti PD1/PD-L1 monoclonal antibodies (IO). Ann Oncol. 2017;28 Suppl 5:v460-96.

8 Saâda-Bouzid E, Defaucheux C, Karabajakian A, Coloma VP, Servois V, Paoletti X et al. Hyperprogression during anti-PD-1/PD-L1 therapy in patients with recurrent and/or metastatic head and neck squamous cell carcinoma. Ann Oncol. 2017 Jul;28(7):1605-11.

9 Yamada Y, Higuchi K, Nishikawa K, Gotoh M, Fuse N, Sugimoto N et al. Phase III study comparing oxaliplatin plus S-1 with cisplatin plus S-1 in chemotherapy-naïve patients with advanced gastric cancer. Ann Oncol. 2015 Jan;26(1):141-8.

10 National Cancer Comprehensive Network [Internet]. Gastric Cancer (Version 5. 2017) [October 13, 2017]. available from: https://www.nccn.org/professionals/physician_gls/pdf/gastric.pdf.

11 Goto K, Endo M, Kusumoto M, Yamamoto N, Ohe Y, Shimizu A et al. Bevacizumab for non-small-cell lung cancer: a nested case control study of risk factors for hemoptysis. Cancer Sci. 2016 Dec;107(12):1837-42.

12 Wolchok JD, Hoos A, O'Day S, Weber JS, Hamid O, Lebbé C et al. Guidelines for the evaluation of immune therapy activity in solid tumors: immune-related response criteria. Clin Cancer Res. 2009 Dec;15(23):741220.

13 Di Giacomo AM, Danielli R, Guidoboni M, Calabrò L, Carlucci D, Miracco C et al. Therapeutic efficacy of ipilimumab, an anti-CTLA-4 monoclonal antibody, in patients with metastatic melanoma unresponsive to prior systemic treatments: clinical and immunological evidence from three patient cases. Cancer Immunol Immunother. 2009 Aug;58(8):1297-306.

14 Fields EC, McGuire WP, Lin L, Temkin SM. Radiation Treatment in Women with Ovarian Cancer: Past, Present, and Future. Front Oncol. 2017 Aug;7:177.

15 Sato H, Suzuki Y, Yoshimoto Y, Noda SE, Murata K, Takakusagi Y et al. An abscopal effect in a case of concomitant treatment of locally and peritoneally recurrent gastric cancer using adoptive $\mathrm{T}$-cell immunotherapy and radiotherapy. Clin Case Rep. 2017 Feb;5(4):380-4. 


\section{Case Reports in Oncology}

Case Rep Oncol 2018;11:143-150

DOI: $10.1159 / 000487477$

(C) 2018 The Author(s). Published by S. Karger AG, Basel www.karger.com/cro

Ogata et al.: Hyperprogressive Disease in the Irradiation Field after a Single Dose of

Nivolumab for Gastric Cancer: A Case Report
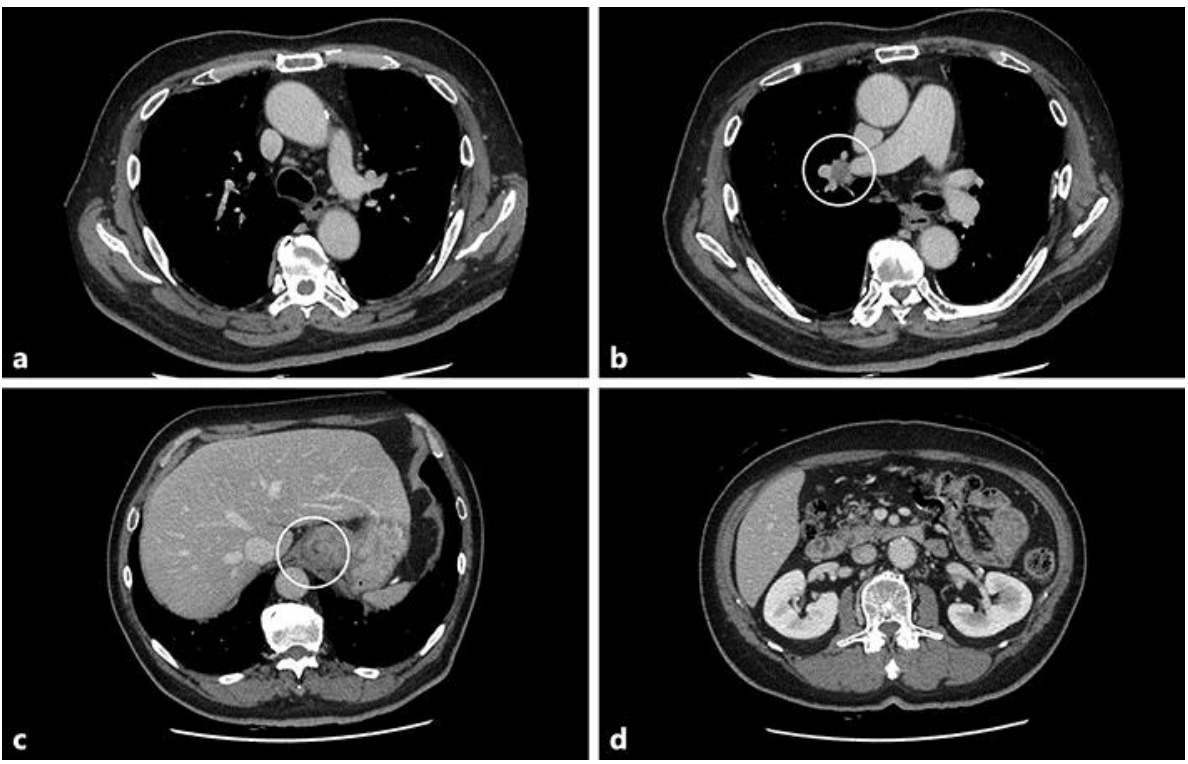

Fig. 1. Computed tomography (CT) findings at diagnosis. a No metastasis was detected in the mediastinal lymph node. b Right hilar lymphadenopathy was observed. c Gastric cardia (primary lesion). d No metastasis to the para-aortic lymph node was observed.
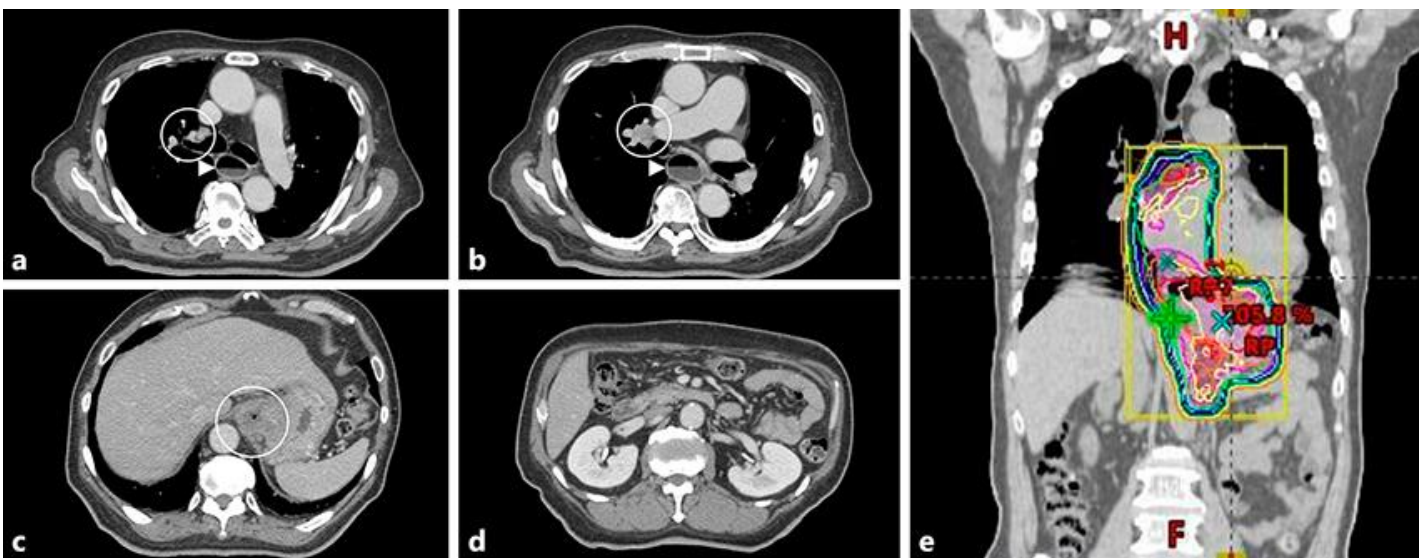

Fig. 2. Computed tomography (CT) findings before radiotherapy. a Metastasis to the pretracheal lymph node at the level of the esophagus. $\mathbf{b}$ Right hilar lymphadenopathy at the level of the esophagus. $\mathbf{c}$ Gastric cardia (primary lesion). d No metastasis was visible in the para-aortic lymph node. e The radiotherapy dose distribution. 


\section{Case Reports in Oncology}

\begin{tabular}{l|l}
\hline Case Rep Oncol 2018;11:143-150 \\
\hline DOI: 10.1159/000487477 & $\begin{array}{l}\text { C 2 2018 The Author(s). Published by S. Karger AG, Basel } \\
\text { www.karger.com/cro }\end{array}$ \\
\hline
\end{tabular}

Ogata et al.: Hyperprogressive Disease in the Irradiation Field after a Single Dose of

Nivolumab for Gastric Cancer: A Case Report

\section{Before Nivolumab}

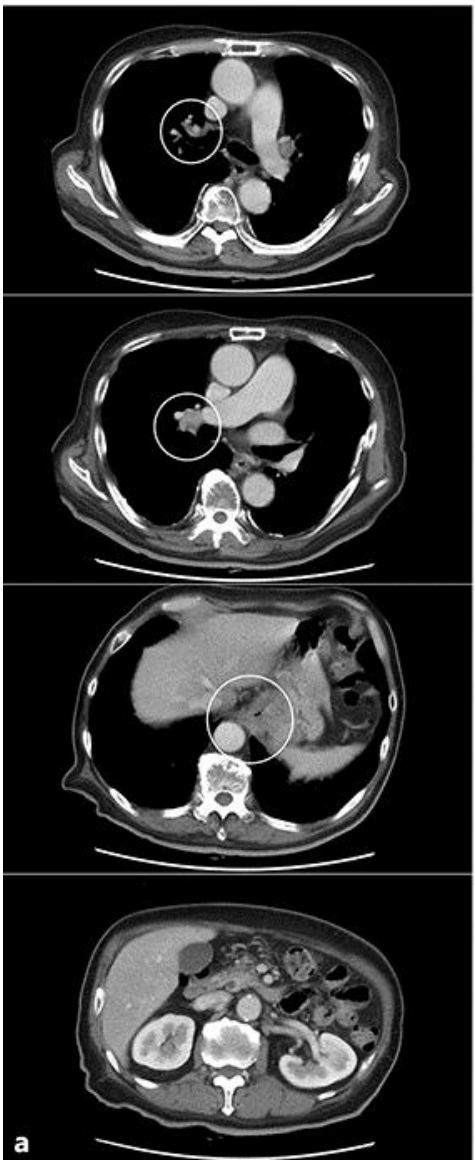

\section{After Nivolumab}

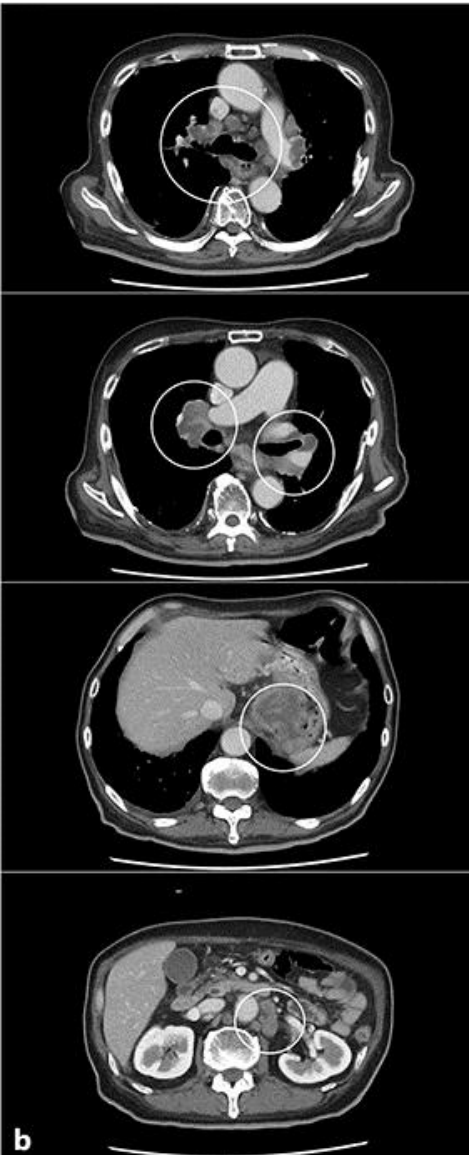

Fig. 3. Clinical course following the administration of nivolumab. a Computed tomography (CT) findings upon completing radiotherapy; the tumor was still visible. $\mathbf{b}$ CT findings 14 days after the first administration of nivolumab; all lesions rapidly progressed. 


\section{Case Reports in Oncology}

Table 1. Laboratory data on the day of the first nivolumab dose

Normal range

\section{Hematological data}

White blood cells

Neutrophils

$10,000 / \mu \mathrm{L}$

$3,900-9,800$

Eosinophils

$87.0 \%$

$0.0 \%$

Basophils

$0.0 \%$

Monophils

$8.0 \%$

Lymphocytes

$5.0 \%$

Red blood cells

$451 \times 10^{4} / \mu \mathrm{L}$

$15.3 \mathrm{~g} / \mathrm{dL}$

410-570 $\times 10^{4}$

Hemoglobin

$28.1 \times 10^{4} / \mu \mathrm{L}$

13.4-17.6

$13.0-37.0 \times 10^{4}$

\section{Immunological data}

TSH

Free T4

$1.00 \mu \mathrm{U} / \mathrm{mL} \quad 0.50-5.00$

ACTH

$1.56 \mathrm{ng} / \mathrm{dL}$

$0.90-1.70$

Cortisol

$20.8 \mathrm{pg} / \mathrm{mL}$

$7.2-63.3$

$18.8 \mu \mathrm{g} / \mathrm{dL}$

7.1-19.6

\section{Biochemistry data}

Total protein

Albumin

$6.8 \mathrm{~g} / \mathrm{dL}$

6.5-8.5

Total bilirubin

$3.4 \mathrm{~g} / \mathrm{dL}$

3.9-4.9

AST

ALT

$1.0 \mathrm{mg} / \mathrm{dL}$

$0.2-1.2$

$21 \mathrm{U} / \mathrm{L}$

8-40

LDH

$13 \mathrm{U} / \mathrm{L}$

8-40

BUN

$184 \mathrm{U} / \mathrm{L}$

120-250

Creatinine

$18.9 \mathrm{mg} / \mathrm{dL}$

8.0-20.0

$\mathrm{Na}$

$0.72 \mathrm{mg} / \mathrm{dL}$

$0.60-1.10$

$135 \mathrm{mEq} / \mathrm{L}$

136-148

$\mathrm{Ca}$

$3.7 \mathrm{mEq} / \mathrm{L}$

3.5-5.3

$9.1 \mathrm{mg} / \mathrm{dL}$

8.0-10.0

\section{Tumor markers}

CEA

CA19-9

$5.5 \mathrm{ng} / \mathrm{mL}$

$20.7 \mathrm{U} / \mathrm{mL}$
$<5.0$

$<37.0$

ACTH, adrenocorticotropic hormone; ALT, alanine aminotransferase; AST, aspartate aminotransferase; BUN, blood urea nitrogen; Ca, calcium; CA19-9, carbohydrate antigen 19-9; CEA, carcinoembryonic antigen; K, potassium; LDH, lactate dehydrogenase; Na, sodium; T4, thyroxine; TSH, thyroid-stimulating hormone. 